\title{
Benefits of Incremental Hemodialysis Seen in a Historical Cohort Study
}

\author{
Weisheng Chen' \\ Mengjing Wang ${ }^{1,2}$ \\ Minmin Zhang ${ }^{1}$ \\ Weichen Zhang' \\ Jun Shi' \\ Jiamin Weng' \\ Bihong Huang' \\ Kamyar Kalantar-Zadeh (iD ${ }^{3-5}$ \\ Jing Chen ${ }^{1,2}$ \\ 'Division of Nephrology, Huashan Hospital, \\ Fudan University, Shanghai, People's \\ Republic of China; ${ }^{2}$ National Clinical \\ Research Center for Aging and Medicine, \\ Huashan Hospital, Fudan University, \\ Shanghai, People's Republic of China; \\ ${ }^{3}$ Harold Simmons Center for Kidney \\ Disease Research and Epidemiology, \\ Division of Nephrology and Hypertension, \\ University of California Irvine Medical \\ Center, Orange, CA, USA; ${ }^{4}$ Fielding School \\ of Public Health at UCLA, Los Angeles, CA, \\ USA; ${ }^{5}$ Los Angeles Biomedical Research \\ Institute at Harbor-UCLA, Torrance, \\ CA, USA
}

Correspondence: Mengjing Wang; Jing

Chen

Division of Nephrology, Huashan Hospital, Fudan University, 12 Middle Wulumuqi Road, Shanghai, People's

Republic of China

Tel +86 21 52889393; +86 2l 52889387

Fax +86 2I 52889325; +86 2I 52888304

Email fiyona27@।26.com;

chenjing1998@fudan.edu.cn
Purpose: Previous research on incremental hemodialysis transition has mainly focused on one or two benefits or prognoses. We aimed to conduct a comprehensive analysis by investigating whether incremental hemodialysis was simultaneously associated with adequate dialysis therapy, stable complication indicators, long-lasting arteriovenous vascular access, and long-lasting preservation of residual kidney function (RKF) without increasing mortality or hospitalization.

Patients and Methods: Incident hemodialysis patients from Huashan Hospital in Shanghai, China, over the period of 2012 to 2019, were enrolled and followed every three months until death or the time of censoring. Changes in complication indicators from baseline to all post-baseline visits were analyzed by mixed-effects models. The outcomes of RKF loss, arteriovenous vascular access complications, and the composite of all-cause mortality and cardiovascular events were compared between incremental and conventional hemodialysis by Cox proportional hazards model.

Results: Of the 113 patients enrolled in the study, 45 underwent incremental and 68 conventional hemodialysis. There were no significant differences in the changes from baseline to postbaseline visits in complication indicators between the two groups. Incremental hemodialysis reduced the risks of RKF loss (HR, 0.33; 95\% CI, 0.14-0.82), de novo arteriovenous access complication (HR, $0.26 ; 95 \% \mathrm{CI}, 0.08-0.82$ ), and recurrent arteriovenous access complications under the Andersen-Gill (AG) model (HR, 0.27; 95\% CI, 0.10-0.74) and the Prentice, Williams and Peterson Total Time (PWP-TT) model (HR, 0.31; 95\% CI, 0.12-0.80). There were no significant differences in all-cause hospitalization or the composite outcome between groups.

Conclusion: Incremental hemodialysis is an effective dialysis transition strategy that preserves RKF and arteriovenous access without affecting dialysis adequacy, patient stability, hospitalization risk and mortality risk. Randomized controlled trials are warranted.

Keywords: incremental hemodialysis, arteriovenous vascular access, residual kidney function, hospitalization, mortality

\section{Introduction}

Thrice-weekly hemodialysis has been considered a standard renal replacement therapy (RRT) since the 1970s. ${ }^{1,2}$ Recently, an increasing number of patients have progressed to end-stage renal disease (ESRD) and initiated hemodialysis therapy with residual kidney function (RKF). ${ }^{3,4}$ Thus, controversy has arisen concerning the abrupt transition from non-dialysis-dependent chronic kidney disease to a thrice-weekly fixed hemodialysis schedule. ${ }^{2,4-8}$ Incremental hemodialysis, a strategy in which the hemodialysis dose is gradually intensified according to the degree of RKF among incident hemodialysis patients, was proposed. ${ }^{2,5,8}$ In most cases, incremental hemodialysis refers to incident hemodialysis patients being prescribed hemodialysis from once weekly to twice weekly and then thrice weekly according to RKF. 5,8 
It has been reported that incremental hemodialysis was associated with preservation of $\mathrm{RKF},{ }^{6,9,10}$ lower serum $\beta 2$-microglobulin, ${ }^{11,12}$ and lower erythropoiesis-stimulating agent consumption and erythropoietin resistance index. ${ }^{10,11}$ Recently, the clinical outcomes of incremental hemodialysis were studied, and mortality was the main focus. ${ }^{6,10,13}$ To date, a comprehensive analysis of whether incremental hemodialysis could simultaneously maintain sufficient adequacy of dialysis and the stability of complication indicators while delaying the loss of residual kidney function without increasing mortality or cardiovascular disease has not been reported. Moreover, protection of arteriovenous vascular access has been proposed but not examined in a cohort of incremental hemodialysis patients. ${ }^{14,15}$

In China, a total of $26 \%$ of ESRD patients have been dialyzing twice weekly, compared with fewer than $5 \%$ in other Dialysis Outcomes and Practice Pattern Study (DOPPS) regions. ${ }^{16}$ Thus, evidence on the safety and benefits of incremental hemodialysis is even more urgent in China than in any other country. Our center has implemented incremental hemodialysis for nearly 10 years with careful and regular monitoring of the symptoms and signs of patients. Therefore, we conducted a historical cohort study to comprehensively investigate the association of incremental hemodialysis with RKF loss, complications of arteriovenous access, all-cause hospitalization and the composite outcome of all-cause mortality and cardiovascular events among incident hemodialysis patients. We also explored the changes in complication-related clinical and laboratory values over the first year among patients on incremental hemodialysis and then compared all the values between the incremental and the conventional hemodialysis.

\section{Patients and Methods Study Population}

We performed a historical cohort study using the data of incident hemodialysis patients aged over 18 years in the Hemodialysis Centre, Huashan Hospital, Shanghai, China, between 2012 and 2019. Of the 137 incident hemodialysis patients who were treated with in-center hemodialysis, 9 were excluded for being treated temporarily, and 15 were excluded for having missing data on urine output or having urine output less than $200 \mathrm{~mL} /$ day at baseline (Supplementary Figure S2). Our final study population consisted of 113 patients. Patients who initiated once- or twice-weekly hemodialysis for at least six months and who subsequently transitioned to a thrice-weekly regimen as RKF declined were categorized as the incremental group. Those who underwent thrice-weekly hemodialysis or transitioned from infrequent hemodialysis to thrice-weekly hemodialysis within six months were categorized as the conventional group. Six months was decided all from clinical practice for it covered the transition from non-dialysis CKD to dialysis and the evaluation for the hemodialysis adequacy and all the complications. It is an enough period to evaluate whether hemodialysis regimens fitted patients. Those who had undergone once-weekly or twice-weekly hemodialysis for palliative purposes or during recovery from acute kidney injury were not included in our cohort. Patients were followed up from the first day of hemodialysis to the end of the second year or the day of censoring for death, transferring to another center, transplantation, or the end of the study (January 17, 2020).

\section{Demographic, Clinical, and Laboratory Values}

Information for age, sex, body mass index (BMI), comorbid conditions, and the primary causes of kidney disease at baseline was obtained from the electronic database of the Hemodialysis Centre. The baseline estimated glomerular filtration rate (eGFR) before hemodialysis initiation was calculated using the Modification of Diet in Renal Disease (MDRD) equation, and the urine output was measured at the same time. All patients visited the doctor with laboratory tests for the regular assessment of complications in January, April, July, and October every year. The results of the first regular visit, which was within three months after hemodialysis initiation, were considered as the baseline.

Blood samples were drawn using uniform techniques in our center at the second hemodialysis session or the first hemodialysis session when patients receiving morethan once-weekly hemodialysis or once-weekly hemodialysis, respectively, and transported to the Department of Clinical Laboratory, typically within two hours. Laboratory values were measured by automated and standardized methods. Furthermore, patients were encouraged to collect 24-hour urine samples on the last day of the interdialytic interval before the hemodialysis session when laboratory tests were to be performed at the upcoming regular visit, from which residual kidney urea clearance (KRU) was calculated. In addition, the values of ultrafiltration volume, pre-dialysis weight, systolic blood pressure, diastolic blood pressure, and dialysis hours for each patient during each regular-visit month were averaged for the following analysis of this 
study. The single-pool Kt/V delivered by hemodialysis was calculated by the second-generation Daugirdas' equation. ${ }^{17}$ The urea reduction ratio (URR) was the fractional reduction of urea during hemodialysis.

\section{Clinical Outcomes}

Outcomes of interest were as follows: 1) RKF loss; 2) time to first complication and time to recurrent complications of arteriovenous vascular access; 3) all-cause hospitalization; and 4) the composite outcome of mortality and cardiovascular events. Cardiovascular events were defined as attacks due to myocardial infarction, congestive heart failure, hospitalization for myocardial ischemia, arrhythmia, or stroke. RKF loss was defined as a urine output less than $200 \mathrm{~mL}$ per 24 hours. Types of arteriovenous access included arteriovenous fistula and graft. Vascular access complications referred to failure, stenosis, or thrombosis of the arteriovenous vascular access that necessitated surgical interventions, including percutaneous transluminal angioplasty. All medical events that happened in either our hospital or other hospitals were documented in our center's database in routine clinical practice.

\section{Statistical Analysis}

Continuous variables were expressed as mean \pm standard deviation (SD) or median with interquartile range (IQR), and categorical variables were expressed as percentages or ratios. The differences between groups were examined using the $t$-test, Wilcoxon's rank sum test, the $\chi^{2}$ test or Fisher's exact test, as appropriate. The trends of laboratory values across the first four regular visits were examined by Cuzick's test. The incidence rate was expressed as the number of cases per 100 person-years. The decline rate of urine output was defined as the slope between the urine output at baseline and the last follow-up urine volume over time.

Changes from baseline to all post-baseline visits in blood pressure, log-transformed NT-proBNP, hemoglobin, potassium, carbon dioxide combining power $\left(\mathrm{CO}_{2} \mathrm{CP}\right)$, calcium, phosphate and log-transformed intact parathyroid hormone (iPTH) were analyzed by a maximum-likelihood, mixedeffects repeated-measures models (MMRM). The model included the above parameter as a response variables and treatment, visit, and the treatment $\times$ visit interaction, age, sex, BMI, diabetes, baseline urine output and eGFR as covariates.

The risk (hazard ratio, HR) of RKF loss, the risk of the composite outcome of all-cause mortality and cardiovascular events, and the time to the first complication of arteriovenous access were compared between the incremental and the conventional hemodialysis by the Kaplan-Meier curve, the Log rank test, and the Cox proportional hazards model. Arteriovenous access complications could occur more than once for an individual patient. The time to recurrent complications of arteriovenous access was examined by the AndersenGill model (AG model) and the Prentice, Williams and Peterson Total Time model (PWP-TT model). ${ }^{18}$ The incidence rate differences in all-cause hospitalization or arteriovenous access complications were examined by the negative binomial model. To adjust the cofounders between groups, two levels of adjustment were performed in all models: 1) Model 1, which included age, sex, BMI, diabetes, urine output, eGFR and systolic blood pressure at baseline and 2) Model 2, which included covariates in Model 1 plus log-transformed NTproBNP, albumin and C-reactive protein at baseline.

All statistical analyses were performed with Stata, version 16.0 (StataCorp LLC). A $P$-value less than 0.05 was considered statistically significant.

\section{Results}

\section{Baseline Characteristics}

The cohort included 45 patients undergoing incremental hemodialysis and 68 undergoing conventional hemodialysis. Baseline characteristics between the two groups are shown in Table 1. Compared with the conventional group, patients in the incremental group were younger and had a lower prevalence of diabetes. The baseline ultrafiltration volume, systolic blood pressure and NT-proBNP were lower, while serum albumin and urine output at baseline were higher in the incremental group.

\section{Comparisons of Clinical and Laboratory Values Between Groups}

In the incremental group, the percentages of those who transitioned to thrice-weekly hemodialysis were $17.1 \%$ (95\% CI, $8.5 \%-32.6 \%)$ and $31.5 \%(95 \% \mathrm{CI}, 19.1 \%-49.1 \%)$ at the end of the first and second years, respectively, estimated by Kaplan-Meier curve (Supplementary Figure S1). In the first year of incremental hemodialysis, most values including blood pressure, serum potassium, $\mathrm{iPTH}, \mathrm{CO}_{2} \mathrm{CP}$, and NTproBNP remained stable across the four regular visits $(P$ for trend $>0.05$; Table 2). The exceptions were that ultrafiltration volume and creatinine had upward trends $(P$ for trend $<0.05$; Table 2). Moreover, there were no significant differences in the overall changes from baseline to all post-baseline visits in NTproBNP, blood pressure, calcium, phosphate, $\mathrm{PTH}$, hemoglobin, potassium and $\mathrm{CO}_{2} \mathrm{CP}(P>0.05$; Table 3$)$. In the subgroup analysis, no significant difference was found in stdKt/V 
Table I Baseline Characteristics of Incident Hemodialysis Patients by Hemodialysis Regimen

\begin{tabular}{|c|c|c|c|}
\hline Characteristics & Incremental Group $(N=45)$ & Conventional Group $(N=68)$ & $\mathbf{P}$ \\
\hline Age (years) & $56.3 \pm 14.3$ & $61.9 \pm 13.8$ & 0.04 \\
\hline Male, n (\%) & $22(48.9)$ & $4 I(60.3)$ & 0.23 \\
\hline Body mass index $\left(\mathrm{kg} \cdot \mathrm{m}^{-2}\right)$ & $22.1 \pm 2.8$ & $22.5 \pm 3.9$ & 0.64 \\
\hline Primary kidney disease & & & 0.01 \\
\hline Diabetes, n (\%) & $4(8.9)$ & $25(36.8)$ & \\
\hline Hypertension, n (\%) & $5(11.1)$ & $7(10.3)$ & \\
\hline Glomerulonephritis, n (\%) & $25(55.6)$ & $21(30.9)$ & \\
\hline Polycystic kidney disease, n (\%) & $6(13.3)$ & $6(8.8)$ & \\
\hline Others/Unknown, n (\%) & $5(11.1)$ & $9(13.2)$ & \\
\hline \multicolumn{4}{|l|}{ Comorbidity } \\
\hline Diabetes mellitus, n (\%) & $8(17.8)$ & $26(38.2)$ & 0.02 \\
\hline Cardiovascular disease, n (\%) & $6(13.3)$ & $15(22.1)$ & 0.24 \\
\hline \multicolumn{4}{|l|}{ Dialysis-related index } \\
\hline Urine output $(\mathrm{mL} / 24 \mathrm{~h})$ & $1566.2 \pm 533.9$ & $1129.4 \pm 521.9$ & $<0.001$ \\
\hline eGFR $\left(\mathrm{mL} / \mathrm{min} / \mathrm{I} .73 \mathrm{~m}^{2}\right)$ & $6.71(5.11,8.97)$ & $6.39(4.72,9.45)$ & 0.90 \\
\hline Ultrafiltration $(\mathrm{mL})$ & $1268.3 \pm 730.3$ & $1975.6 \pm 700.5$ & $<0.001$ \\
\hline Predialysis weight $(\mathrm{kg})$ & $60.7 \pm 10.3$ & $61.6 \pm 13.6$ & 0.71 \\
\hline $\mathrm{SBP}(\mathrm{mmHg})$ & $|3| .3 \pm 14.9$ & $140.8 \pm 16.0$ & 0.002 \\
\hline $\mathrm{DBP}(\mathrm{mmHg})$ & $76.4 \pm 10.6$ & $78.1 \pm 10.6$ & 0.42 \\
\hline Dialytic treatment time (hours/session) & $3.98 \pm 0.32$ & $3.94 \pm 0.12$ & 0.31 \\
\hline $\mathrm{spKt} / \mathrm{V}$ & $1.35 \pm 0.26$ & $1.27 \pm 0.33$ & 0.13 \\
\hline URR & $0.69 \pm 0.07$ & $0.65 \pm 0.10$ & 0.03 \\
\hline \multicolumn{4}{|l|}{ Laboratory measures } \\
\hline Albumin (g/dL) & $4.02 \pm 3.37$ & $3.72 \pm 4.35$ & $<0.001$ \\
\hline Hemoglobin (g/dL) & $9.69 \pm 1.11$ & $9.54 \pm 1.33$ & 0.55 \\
\hline Calcium (mg/dL) & $8.77 \pm 0.91$ & $8.79 \pm 1.02$ & 0.90 \\
\hline Phosphate (mg/dL) & $4.85 \pm 1.09$ & $5.29 \pm 1.68$ & 0.13 \\
\hline iPTH (pg/mL) & $204(107,336)$ & $220(119,336)$ & 0.85 \\
\hline $\mathrm{CO}_{2} \mathrm{CP}(\mathrm{mmol} / \mathrm{L})$ & $21.6 \pm 4.2$ & $21.5 \pm 3.9$ & 0.85 \\
\hline Potassium (mg/dL) & $4.81 \pm 0.75$ & $4.67 \pm 0.74$ & 0.34 \\
\hline NT-proBNP (pg/mL) & $116 I(733,402 I)$ & $2867(1124,6196)$ & $<0.001$ \\
\hline Creatinine (mg/dL) & $8.46 \pm 2.12$ & $8.20 \pm 2.44$ & 0.55 \\
\hline SUN (mg/dL) & $77.2 \pm 18.1$ & $71.0 \pm 18.8$ & 0.09 \\
\hline C-reactive protein & & & 0.20 \\
\hline$<10 \mathrm{mg} / \mathrm{dL}(\%)$ & $43(95.6)$ & $59(86.8)$ & \\
\hline$\geq 10 \mathrm{mg} / \mathrm{dL}(\%)$ & $2(4.4)$ & $9(13.2)$ & \\
\hline
\end{tabular}

Notes: Continuous data presented as mean \pm standard deviation or median (interquartile range); categorical data presented as number (percent).

Abbreviations: eGFR, estimated glomerular filtration rate; iPTH, intact parathyroid hormone; $\mathrm{CO}_{2} \mathrm{CP}$, carbon dioxide combining power; $\mathrm{NT}$-proBNP, $\mathrm{N}$-terminal proB-type natriuretic peptide; SUN, serum urea nitrogen; URR, urea reduction ratio.

over the first four visits $\left(P_{\text {for group }}=0.14 ; P_{\text {for group } \times \text { time interaction }}\right.$ $=0.59 ;$ Supplementary Table S3).

\section{Association of Incremental Hemodialysis with Residual Kidney Function}

The decline rate of urine output in the incremental group was significantly lower than that in the conventional group [-33.4 $\mathrm{mL} / \mathrm{month}$ (IQR, -76.7 to $-19.4 \mathrm{~mL} / \mathrm{month}) \mathrm{vs}$
$-70.4 \mathrm{~mL} / \mathrm{month}$ (IQR, -155.5 to $-33.0 \mathrm{~mL} / \mathrm{month}) ; P<$ 0.001]. The mean follow-up duration was $13.4 \pm 7.9$ months; during this period, 46 patients occurred outcomes of RKF loss, 37 occurred in the conventional group. A decrease in unadjusted risk for RKF loss was observed for incremental hemodialysis $\left(P_{\text {log-rank }}<0.001\right.$, Figure $1 \mathrm{~A}$; HR, $0.23,95 \%$ CI, 0.11-0.47, $P<0.001$, Table 4). After controlling for covariates, this association persisted in Model 1 (HR, 0.37; 95\% CI, 0.16-0.82; $P=0.01$ ) and Model 2 (HR, 0.33; 95\% 
Table 2 The Changes in Clinical and Laboratory Values Over the First Four Regularly Visits After Initiating Hemodialysis Therapy Among Patients with Incremental Hemodialysis

\begin{tabular}{|c|c|c|c|c|c|}
\hline Characteristics & QI $(n=45)$ & Q2 $(n=45)$ & Q3 $(n=43)$ & Q4 $(n=41)$ & $P_{\text {for trend }}$ \\
\hline Ultrafiltration $(\mathrm{mL})$ & $1278(670,1686)$ & $1339(752,2314)$ & I77I $(748,28 \mid 4)$ & $|72|(826,2375)$ & 0.02 \\
\hline Predialysis weight $(\mathrm{kg})$ & $60.7 \pm 10.3$ & $61.5 \pm 10.5$ & $62.7 \pm 10.4$ & $62.3 \pm 10.3$ & 0.42 \\
\hline SBP $(\mathrm{mmHg})$ & $131.3 \pm 14.9$ & $131.5 \pm 15.2$ & $130.9 \pm 14.6$ & $132.9 \pm 14.4$ & 0.78 \\
\hline $\mathrm{DBP}(\mathrm{mmHg})$ & $76.4 \pm 10.6$ & $76.3 \pm 12.0$ & $78.0 \pm 12.1$ & $77.2 \pm 9.7$ & 0.58 \\
\hline Dialytic treatment time (hours) & $3.98 \pm 0.32$ & $4.04 \pm 0.32$ & $4.03 \pm 0.37$ & $4.00 \pm 0.33$ & 0.78 \\
\hline $\mathrm{spK} t / \mathrm{V}$ & $1.35 \pm 0.26$ & $1.35 \pm 0.25$ & $1.35 \pm 0.25$ & $1.38 \pm 0.27$ & 0.76 \\
\hline URR & $0.69 \pm 0.07$ & $0.68 \pm 0.07$ & $0.68 \pm 0.06$ & $0.69 \pm 0.07$ & 0.97 \\
\hline \multicolumn{6}{|l|}{ Laboratory variables } \\
\hline Albumin $(\mathrm{g} / \mathrm{dL})$ & $4.02 \pm 0.34$ & $4.04 \pm 0.34$ & $4.03 \pm 0.34$ & $4.06 \pm 0.28$ & 0.71 \\
\hline Hemoglobin $(g / d L)$ & $9.69 \pm 1.11$ & $10.64 \pm 1.26$ & $10.58 \pm 1.39$ & $10.32 \pm 1.16$ & 0.05 \\
\hline Calcium (mg/dL) & $8.77 \pm 0.91$ & $9.05 \pm 1.05$ & $8.86 \pm 1.01$ & $9.06 \pm 1.29$ & 0.42 \\
\hline Phosphate $(\mathrm{mg} / \mathrm{dL})$ & $4.85 \pm 1.09$ & $5.11 \pm 1.45$ & $5.15 \pm 1.44$ & $4.67 \pm 1.53$ & 0.63 \\
\hline iPTH (pg/mL) & $204(107,336)$ & $174(64,391)$ & $181(72,302)$ & $154(93,222)$ & 0.07 \\
\hline $\mathrm{CO}_{2} \mathrm{CP}(\mathrm{mmol} / \mathrm{L})$ & $21.6 \pm 4.2$ & $20.8 \pm 4.1$ & $20.6 \pm 3.2$ & $21.7 \pm 3.3$ & 0.77 \\
\hline Potassium (mg/dL) & $4.81 \pm 0.75$ & $4.69 \pm 0.60$ & $4.89 \pm 0.72$ & $4.74 \pm 0.75$ & 0.80 \\
\hline NT-proBNP (pg/mL) & $116 \mid(733,2595)$ & $1100(607,1931)$ & $1252(738,2183)$ & $1454(9 \mid 8,3378)$ & 0.17 \\
\hline Creatinine $(\mathrm{mg} / \mathrm{dL})$ & $8.46 \pm 2.12$ & $9.29 \pm 2.51$ & $10.25 \pm 3.08$ & $10.15 \pm 3.00$ & 0.001 \\
\hline SUN (mg/dL) & $77.2 \pm 18.1$ & $79.1 \pm 16.5$ & $84.9 \pm 20.2$ & $84.9 \pm 20.2$ & 0.36 \\
\hline C-reactive protein & & & & & 0.24 \\
\hline$<10 \mathrm{mg} / \mathrm{dL}(\%)$ & $43(95.6)$ & $44(97.8)$ & $4 \mathrm{I}(95.3)$ & $37(90.2)$ & \\
\hline$\geq 10 \mathrm{mg} / \mathrm{dL}(\%)$ & $2(4.4)$ & I (2.2) & $2(4.7)$ & $4(9.8)$ & \\
\hline
\end{tabular}

Notes: Continuous data presented as mean \pm standard deviation or median (interquartile range); categorical data presented as number (percent). QI-4, the first to fourth quarterly visits after hemodialysis initiation.

Abbreviations: eGFR, estimated glomerular filtration rate; iPTH, intact parathyroid hormone; $\mathrm{CO}_{2} \mathrm{CP}$, carbon dioxide combining power; NT-proBNP, N-terminal proB-type natriuretic peptide; SUN, serum urea nitrogen; URR, urea reduction ratio.

CI, 0.14-0.82; $P=0.02$ ) (Table 4). The association between hemodialysis regimens and RKF was diminished after ultrafiltration volume at baseline was added to the adjustment model.

\section{Association of Incremental Hemodialysis with Complications of Arteriovenous Access}

Three patients in the incremental group and six patients in the conventional group were excluded from the main cohort for failure of arteriovenous access maturation or censoring before arteriovenous access maturation. The mean follow-up duration was $17.0 \pm 7.9$ months; during this period, 36 arteriovenous outcome complications occurred, 30 occurred in the conventional group. The incidence rates of arteriovenous access complications in the two groups were 8.5 and 29.8 per 100 person-years, respectively. Incremental hemodialysis was associated with a lower incidence rate of arteriovenous access complications under the unadjusted and adjusted negative binomial models (Supplementary Table S1). A lower risk of having an arteriovenous access complication was also observed for incremental hemodialysis by the Log rank test and the Cox model, with an adjusted HR of $0.26(95 \%$ CI, 0.08-0.82) in Model 2 (Figure 1B; Table 5). Moreover, the adjusted risk of recurrent complications of arteriovenous access was lower for incremental hemodialysis under the AG model (HR, 0.27; 95\% CI, 0.10-0.74; $P=0.01$ ) and the PWP-TT model (HR, 0.31; 95\% CI, 0.12-0.80; $P=0.02$ ) (Table 5).

\section{Association of Incremental Hemodialysis with Hospitalization and the Composite Outcome}

The mean follow-up duration was $18.9 \pm 6.9$ months; during this period, 18 patients occurred outcomes of the composite outcome, 14 occurred in the conventional group. The incidence rate of all-cause hospitalization was lower in the incremental group than in the conventional group under the unadjusted negative binomial model (IRR, $0.57 ; 95 \% \mathrm{CI}, 0.34-0.93 ; P=0.03$ ), but this association was not significant under the adjusted negative binomial 
Table 3 Repeated-Measures Analysis of Changes in Laboratory Values and Blood Pressure Between Groups from Baseline to PostBaseline Visits

\begin{tabular}{|c|c|c|c|c|c|c|c|}
\hline & \multicolumn{2}{|c|}{ Second Visit } & \multicolumn{2}{|c|}{ Third Visit } & \multicolumn{2}{|c|}{ Fourth Visit } & \multirow[b]{2}{*}{$P^{c}$} \\
\hline & Diff $(95 \% \mathrm{CI})^{a}$ & $P^{b}$ & Diff $(95 \% \mathrm{Cl})^{a}$ & $P^{b}$ & Diff $(95 \% \mathrm{Cl})^{\mathrm{a}}$ & $P^{b}$ & \\
\hline $\begin{array}{l}\text { Log-transformed NT-proBNP } \\
\text { Conventional group }(n=68) \\
\text { Incremental group }(n=45)\end{array}$ & $\begin{array}{c}0.10(-0.09,0.30) \\
-0.02(-0.26,0.22)\end{array}$ & 0.44 & $\begin{array}{c}-0.01(-0.21,0.19) \\
0.04(0.21,0.29)\end{array}$ & 0.75 & $\begin{array}{l}0.10(-0.11,0.30) \\
0.22(-0.03,0.47)\end{array}$ & 0.46 & 0.50 \\
\hline $\begin{array}{l}\text { Systolic blood pressure } \\
\text { Conventional group }(n=68) \\
\text { Incremental group }(n=45)\end{array}$ & $\begin{array}{c}-2.82(-5.84,0.20) \\
0.20(-3.51,3.91)\end{array}$ & 0.22 & $\begin{array}{l}-2.09(-5.12,0.95) \\
-0.77(-4.53,2.99)\end{array}$ & 0.59 & $\begin{array}{c}-3.09(-6.23,0.05) \\
1.43(-2.39,5.25)\end{array}$ & 0.07 & 0.30 \\
\hline $\begin{array}{l}\text { Diastolic blood pressure } \\
\text { Conventional group }(n=68) \\
\text { Incremental group }(n=45)\end{array}$ & $\begin{array}{l}-1.74(-3.64,0.16) \\
-0.08(-2.41,2.25)\end{array}$ & 0.28 & $\begin{array}{c}-1.31(-3.22,0.60) \\
1.45(-0.92,3.82)\end{array}$ & 0.08 & $\begin{array}{c}-1.69(-3.66,0.28) \\
1.03(-1.37,3.43)\end{array}$ & 0.09 & 0.25 \\
\hline $\begin{array}{l}\text { Potassium } \\
\text { Conventional group }(n=68) \\
\text { Incremental group }(n=45)\end{array}$ & $\begin{array}{c}0.14(-0.02,0.31) \\
-0.12(-0.32,0.09)\end{array}$ & 0.05 & $\begin{array}{c}0.24(0.07,0.42) \\
0.08(-0.13,0.29)\end{array}$ & 0.23 & $\begin{array}{c}0.18(0.01,0.35) \\
-0.11(-0.32,0.10)\end{array}$ & 0.04 & 0.15 \\
\hline $\begin{array}{l}\mathrm{CO}_{2} \mathrm{CP} \\
\text { Conventional group }(n=68) \\
\text { Incremental group }(n=45)\end{array}$ & $\begin{array}{l}-0.49(-0.52,1.49) \\
-0.85(-2.08,0.38)\end{array}$ & 0.10 & $\begin{array}{l}-0.03(-1.04,0.98) \\
-1.01(-2.26,0.25)\end{array}$ & 0.23 & $\begin{array}{l}0.29(-0.75,1.33) \\
0.04(-1.23,1.30)\end{array}$ & 0.76 & 0.33 \\
\hline $\begin{array}{l}\text { Hemoglobin } \\
\text { Conventional group }(n=68) \\
\text { Incremental group }(n=45)\end{array}$ & $\begin{array}{l}0.92(0.5 \mathrm{I}, \mathrm{I} .33) \\
0.95(0.45,1.45)\end{array}$ & 0.92 & $\begin{array}{l}1.10(0.70,1.51) \\
0.91(0.40,1.41)\end{array}$ & 0.56 & $\begin{array}{l}1.03(0.6 \mathrm{I}, \mathrm{I} .45) \\
0.63(0.12, \mathrm{I} .14)\end{array}$ & 0.23 & 0.55 \\
\hline $\begin{array}{l}\text { Calcium } \\
\text { Conventional group }(n=68) \\
\text { Incremental group }(n=45)\end{array}$ & $\begin{array}{c}0.33(0.04,0.62) \\
0.28(-0.07,0.64)\end{array}$ & 0.84 & $\begin{array}{c}0.4 I(0.12,0.70) \\
0.11(-0.25,0.47)\end{array}$ & 0.20 & $\begin{array}{l}0.26(-0.04,0.56) \\
0.29(-0.07,0.65)\end{array}$ & 0.89 & 0.48 \\
\hline $\begin{array}{l}\text { Phosphate } \\
\text { Conventional group }(n=68) \\
\text { Incremental group }(n=45)\end{array}$ & $\begin{array}{c}-0.08(-0.48,0.33) \\
0.26(-0.24,0.76)\end{array}$ & 0.31 & $\begin{array}{c}-0.08(-0.49,0.33) \\
0.26(-0.25,0.77)\end{array}$ & 0.31 & $\begin{array}{c}0.10(-0.33,0.52) \\
-0.24(-0.76,0.28)\end{array}$ & 0.32 & 0.15 \\
\hline $\begin{array}{l}\text { Log-transformed iPTH } \\
\text { Conventional group }(n=68) \\
\text { Incremental group }(n=45)\end{array}$ & $\begin{array}{l}-0.48(-0.8 I,-0.15) \\
-0.27(-0.68,0.14)\end{array}$ & 0.44 & $\begin{array}{c}-0.46(-0.79,-0.13) \\
-0.19(-0.60,0.22)\end{array}$ & 0.32 & $\begin{array}{l}-0.22(-0.57,0.12) \\
-0.38(-0.80,0.03)\end{array}$ & 0.57 & 0.39 \\
\hline
\end{tabular}

Notes: ${ }^{a}$ Values are adjusted least-squares means and $95 \% \mathrm{Cl}$ estimated from the mixed-effects model. ${ }^{\mathrm{b}}$ Test of significance of treatment group differences by visit (changes from baseline visit to the second visit, third visit or fourth visit between group) from the mixed-effects model. ${ }^{\circ}$ Test of significance between treatment groups for the overall effect (group $\times$ visit) from the mixed-effects model.

Abbreviations: iPTH, intact parathyroid hormone; $\mathrm{CO}_{2} \mathrm{CP}$, carbon dioxide combining power; NT-proBNP, N-terminal pro-B-type natriuretic peptide.

model (Supplementary Table S2). Moreover, the incremental group was not associated with risk of death or the composite outcome by the unadjusted or adjusted Cox model (Figure 1C and D; Table 6).

\section{Discussion}

In the present study, we provide evidence that patients receiving incremental hemodialysis can maintain most of their complication-related clinical and laboratory values stable in the first year. We also found that incremental hemodialysis was significantly associated with preservation of RKF and fewer complications of arteriovenous access. Furthermore, patients receiving incremental hemodialysis were found to have a similar risk of hospitalization, death and the composite outcome as patients receiving conventional hemodialysis.

Most clinical and laboratory values in the first year remained stable among patients with incremental hemodialysis. In a subgroup analysis, we found that the weekly clearance of urea $(\operatorname{stdKt} / \mathrm{V})$ between the two groups was comparable, which means RKF compensated for the reduction in urea clearance when dialysis frequency decreased (Supplementary Table S3). RKF has been reported to have a strong ability to remove fluid and salt, excrete phosphorus, clear middle molecules, and produce endogenous vitamin D and erythropoietin., ${ }^{4-21}$ The increasing trends in ultrafiltration volume and creatinine might still suggest an underlying decline in RKF during 

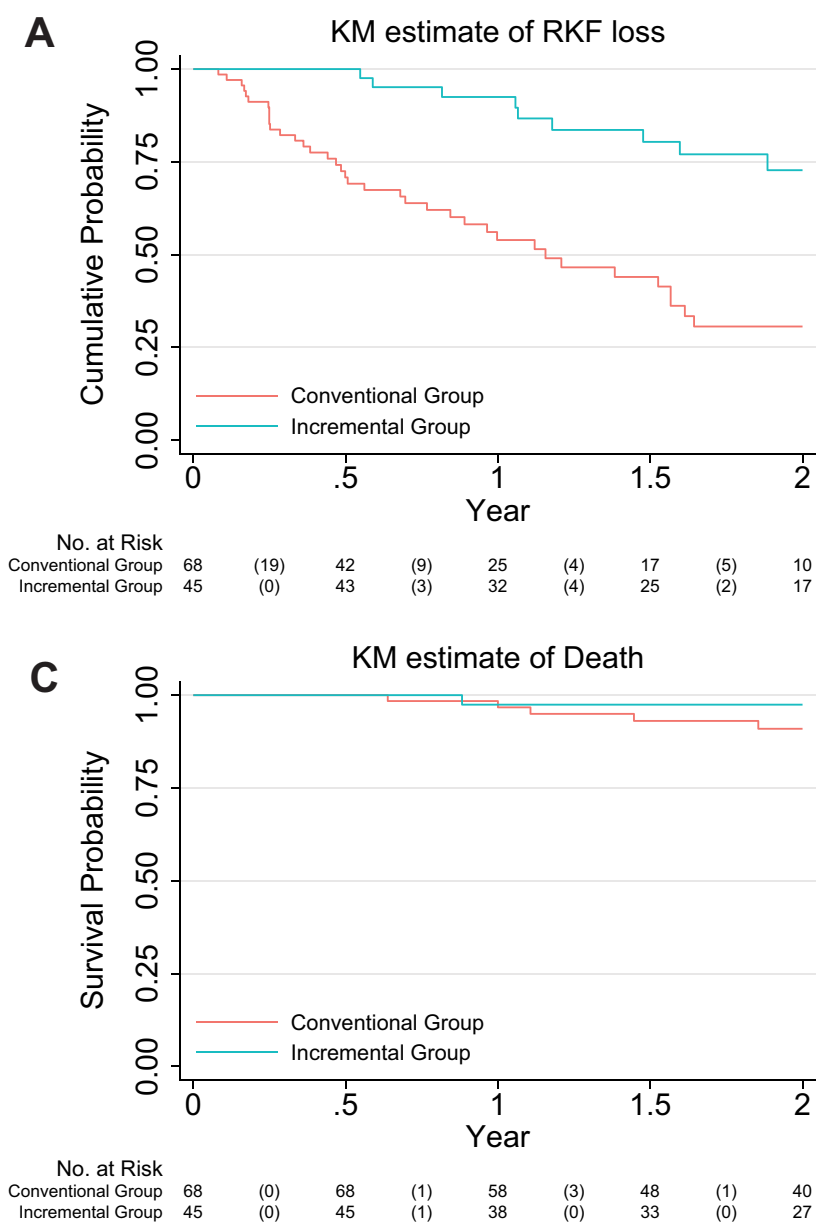

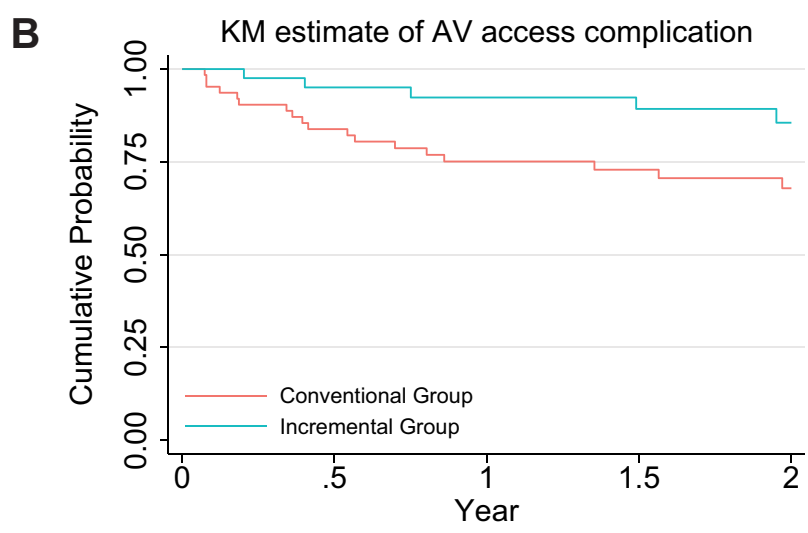

No. at Risk $\begin{array}{cccccccccc}\text { Conventional Group } & 63 & (10) & 50 & (5) & 38 & (1) & 32 & \text { (2) } & 25 \\ \text { Incremental Group } & 42 & (2) & 38 & (1) & 33 & \text { (1) } & 29 & \text { (1) } & 23\end{array}$

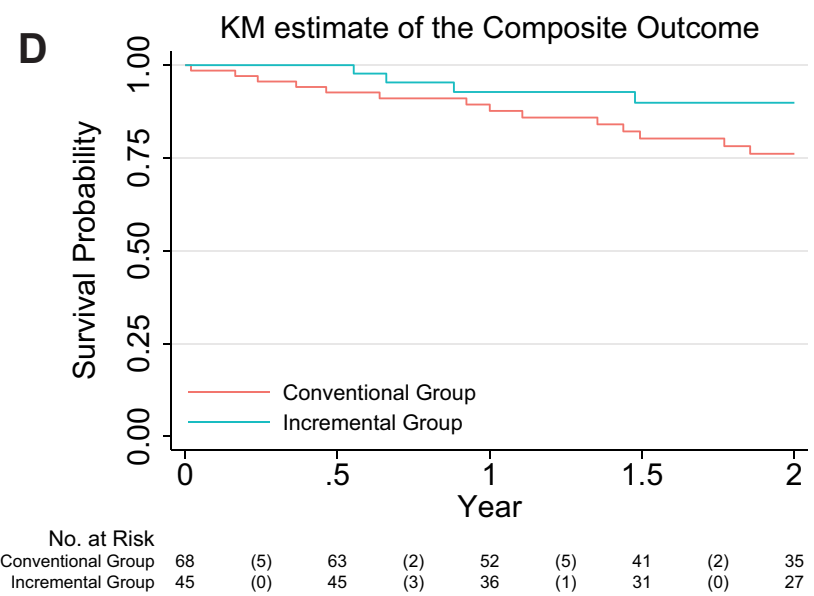

Figure I Kaplan-Meier survival curve for (A) RKF loss, (B) the first arteriovenous access complication, (C) death; (D) the composite outcome of mortality and cardiovascular events. Numbers without parentheses in the risk table show the absolute numbers of patients at risk over time and numbers within parentheses show the absolute numbers of patients with events during a period.

the first year. Unlike a gradual or mild decline in RKF, a significant decline in RKF usually results in uncontrolled hypertension or hypervolemia, and frequent hyperpotassemia and acidosis, which are the indexes in our center to increase hemodialysis frequency among patients receiving

Table 4 Unadjusted and Adjusted Hazard Ratio of RKF Loss by Hemodialysis Regimen

\begin{tabular}{|l|c|c|c|}
\hline Model & $\begin{array}{c}\text { Hazard } \\
\text { Ratio }\end{array}$ & $\begin{array}{c}\text { 95\% Confidential } \\
\text { Interval }\end{array}$ & $P$ \\
\hline Univariate & 0.23 & $0.1 \mathrm{I}, 0.47$ & $<0.00 \mathrm{I}$ \\
Model I & 0.37 & $0.16,0.82$ & $0.0 \mathrm{I}$ \\
Model 2 & 0.33 & $0.14,0.82$ & 0.02 \\
Model I + UFV & 0.45 & $0.20,1.04$ & 0.06 \\
Model 2 + UFV & 0.40 & $0.16,1.05$ & 0.06 \\
\hline
\end{tabular}

Notes: Model I, adjusted for age, sex, BMI, diabetes, urine output, eGFR, and systolic blood pressure at baseline; Model 2, adjusted for Model I plus NT-proBNP, albumin, and C-reactive protein at baseline.

Abbreviation: UFV, ultrafiltration volume at baseline. incremental hemodialysis. Taken together, RKF plays a significant role in implementing incremental hemodialysis.

So far, there has been no evidence that incremental hemodialysis was associated with prolonged longevity of arteriovenous access. In the present study, we first report the association of incremental hemodialysis with a decreased risk of complications of arteriovenous access. This association may arise due to lower intradialytic ultrafiltration and a lower incidence of intradialytic hypotension (IDH). Patients with incremental hemodialysis had better preserved RKF, which may slow the accumulation of fluids and avoid larger-volume intradialytic ultrafiltration. Largevolume ultrafiltration has been directly associated with the frequency of episodes of IDH, which may cause extreme hemodynamic derangements and thus increased the risk of arteriovenous access complications. ${ }^{22-24}$ In addition, more frequent venipunctures in conventional hemodialysis result 
Table 5 Unadjusted and Adjusted Hazard Ratio of Arteriovenous Access Complications by Hemodialysis Regimen

\begin{tabular}{|c|c|c|c|}
\hline Model & $\begin{array}{c}\text { Hazard } \\
\text { Ratio }\end{array}$ & $\begin{array}{c}\text { 95\% Confidential } \\
\text { Interval }\end{array}$ & $\boldsymbol{P}$ \\
\hline Cox Model & 0.36 & $0.13,0.98$ & 0.04 \\
Univariate & 0.27 & $0.09,0.81$ & 0.02 \\
Model I & 0.26 & $0.08,0.82$ & 0.02 \\
Model 2 & & & \\
\hline AG Model & 0.29 & $0.11,0.79$ & 0.02 \\
Univariate & 0.25 & $0.10,0.63$ & 0.003 \\
Model I & 0.27 & $0.10,0.74$ & 0.01 \\
Model 2 & & & 0.02 \\
\hline PWP-TT Model & 0.37 & $0.16,0.86$ & 0.003 \\
Univariate & 0.30 & $0.14,0.66$ & 0.02 \\
Model I & 0.31 & $0.12,0.80$ & \\
Model 2 & & & \\
\hline
\end{tabular}

Notes: Model I, adjusted for age, sex, BMI, diabetes, urine output, eGFR, and systolic blood pressure at baseline; Model 2, adjusted for Model I plus NT-proBNP, albumin, and C-reactive protein at baseline.

Abbreviations: AG Model, Andersen and Gill Cox model; PWP-TT Model, Prentice, Williams and Peterson-Total Time Model.

Table 6 Unadjusted and Adjusted Hazard Ratio of the Death and the Composite Outcome of All-Cause Mortality and Cardiovascular Events by Hemodialysis Regimen

\begin{tabular}{|l|c|c|c|}
\hline Model & $\begin{array}{c}\text { Hazard } \\
\text { Ratio }\end{array}$ & $\begin{array}{c}\text { 95\% Confidential } \\
\text { Interval }\end{array}$ & $\boldsymbol{P}$ \\
\hline $\begin{array}{l}\text { Composite Outcome } \\
\text { Univariate }\end{array}$ & 0.41 & $0.13,1.24$ & $0.1 \mathrm{I}$ \\
Model I & 0.80 & $0.23,2.80$ & 0.72 \\
Model 2 & 0.88 & $0.23,3.43$ & 0.85 \\
\hline Death & & & \\
Univariate & 0.30 & $0.04,2.59$ & 0.28 \\
Model I & 0.96 & $0.08,12.02$ & 0.99 \\
Model 2 & 1.83 & $0.06,52.25$ & 0.72 \\
\hline
\end{tabular}

Notes: Model I, adjusted for age, sex, BMI, diabetes, urine output, eGFR, and systolic blood pressure at baseline; Model 2, adjusted for Model I plus NT-proBNP, albumin, and C-reactive protein at baseline.

in repeated trauma at venipuncture sites and subsequent turbulent blood flow. Both of these consequences may promote profibrotic cytokine production, local inflammation, and neointimal proliferation, which together increase arteriovenous access complications. ${ }^{25,26}$

Several studies have compared mortality between the incremental and the conventional hemodialysis. Some studies reported that the incremental hemodialysis did not increase mortality. ${ }^{6,13}$ In the present study, the outcome of all-cause hospitalization and the composite outcome of all-cause mortality and cardiovascular events were investigated. We found that the composite outcome, death and all-cause hospitalization were not significantly different between groups. This may be related to a stable control of complications, adequate hemodialysis and better RKF preservation as demonstrated in our study. Taken together, the above findings show that patients with RKF may safely be prescribed incremental hemodialysis in their transition to renal replacement therapy.

It is plausible that the observed safety of transition was moderated by longer preservation of RKF. ${ }^{27-29}$ In a previous study, we showed that thrice-weekly hemodialysis in the first year of hemodialysis was associated with a 7.2-fold increased likelihood of RKF loss compared to twice-weekly hemodialysis. ${ }^{9}$ Here, we demonstrated that the decline rate of RKF was slower in the incremental hemodialysis than in the conventional hemodialysis. Notably, this benefit was not traded off against a poorer prognosis as showed in this study. One of the mechanisms whereby RKF among patients with incremental hemodialysis declines more slowly may be that renal perfusion acutely decreases during hemodialysis therapy, resulting in renal ischemia, and that an incremental hemodialysis schedule decreases the frequency of ischemic insults and alleviates renal tissue damage at the initial stage. ${ }^{30,31}$ Membrane bio-incompatibility is one of the causes of inflammation in hemodialysis patients and is an independent risk factor for the progression of kidney function. ${ }^{32-34}$ Incremental hemodialysis may reduce exposure to those factors, which might partially account for RKF preservation.

Overall, it was demonstrated in our study that incremental hemodialysis reduces complications of arteriovenous access and slows the decline of RKF. As we known, hemodialysis patients have referred to their vascular access as their lifeline, which means the vascular access complications may have an adverse impact on hemodialysis experience and health-related quality of life (HRQOL), which may be one of the reasons why HRQOL impairs among patients on hemodialysis. In addition, high RKF was significantly associated with fewer symptom burden. ${ }^{35}$ Overall, incremental hemodialysis may improve the health-related quality of life and symptom burden among hemodialysis patients, whereby the protection of arteriovenous access and residual kidney function. Subsequent studies may need more consideration in HRQOL and symptom burden. 
There were some limitations to our study. This was a historical cohort study, in which two hemodialysis regimens were not assigned randomly; thus, the results may suffer from some confounders such as age, comorbidities and so on. However, we adjusted potential confounders and tried to investigate the independent associations of incremental hemodialysis with clinical outcomes. We also obtained consistent results using the inverse probability weighting method, which is another method to adjust for the baseline imbalance between groups (Supplementary Tables S5 and S6). However, residual confounding factors, such as medications, may still exist. Small sample study was another limitation and low statistical power of small sample size may result in poor ability to detect clinical outcomes of significance. Multicenter study with larger sample size may be warranted in the near future. Moreover, not all patients had KRU records at every regular visit, but estimated urine output was monitored. The standard weekly clearance of urea (stdKt/ V) thus cannot be calculated for all patients. In addition, trajectories of renal function before initiation of long-term hemodialysis have not been considered, which might have an association with the clinical outcome after initiating hemodialysis. Nevertheless, we are the first to report a protective effect of incremental hemodialysis on arteriovenous access. Our comparisons of clinical outcomes between groups are more comprehensive than other studies. We also have summarized a set of clinical criteria in our center to implement incremental hemodialysis, which is based on the experience of 10-year clinical practices and need further verification from cohort studies (Supplementary Table S4).

\section{Conclusion}

Incremental hemodialysis is a strategy to keeping hemodialysis adequate and complications stable and to protect RKF and arteriovenous access without increasing all-cause hospitalization and the composite outcome of mortality and cardiovascular events. This study provides better evidence supporting the implementation of incremental hemodialysis through comprehensive analyses. Our findings lead to an urgent call for randomized controlled trials to support incremental hemodialysis schedule.

\section{Data Sharing Statement}

The data used and/or analyzed during the current study are available from the corresponding author on reasonable request.

\section{Ethics Approval and Informed Consent}

Patients were receiving hemodialysis in accordance with relevant guidelines and regulations. This historical cohort study was examined and approved by the Ethics Committee on Human Research at Huashan Hospital (approval number: KY2019-585) and written informed consents were provided by either participants or legally authorized representatives of patients. This study was conducted in accordance with the Declaration of Helsinki.

\section{Acknowledgments}

The authors are grateful to all participating patients and staff at Hemodialysis Centre, Huashan Hospital.

\section{Funding}

This research was supported, in part, by grants from National Key Research and Development program (2020YFC2005003, and 2018YFC2000204), Shanghai Shenkang Hospital Development Center (SHDC2020CR4014), Shanghai Program for Outstanding Medical Academic Leader (2019LJ03), National Natural Science Foundation of China (81570665, 81730017, and 81600577), Natural Science Foundation of Shanghai (16ZR1449400), and Shanghai Engineering Research Center of AI Assisted Clinical Service forAging-Associated Diseases (19DZ2251700).

\section{Disclosure}

The authors declare no potential conflicts of interest.

\section{References}

1. Scribner BH, Cole JJ, Ahmad S, Blagg CR. Why thrice weekly dialysis? Hemodial Int. 2004;8(2):188-192. doi:10.1111/j.14927535.2004.01094.x

2. Rhee CM, Unruh M, Chen J, Kovesdy CP, Zager P, Kalantar-Zadeh K. Infrequent dialysis: a new paradigm for hemodialysis initiation. Semin Dial. 2013;26(6):720-727. doi:10.1111/sdi.12133

3. O'Hare AM, Wong SP, Yu MK, et al. Trends in the timing and clinical context of maintenance dialysis initiation. J Am Soc Nephrol. 2015;26 (8):1975-1981. doi:10.1681/ASN.2013050531

4. Mathew AT, Obi Y, Rhee CM, Chou JA, Kalantar-Zadeh K. Incremental dialysis for preserving residual kidney function-does one size fit all when initiating dialysis? Semin Dial. 2018;31(4):343-352. doi:10.1111/sdi.12701

5. Kalantar-Zadeh K, Casino FG. Let us give twice-weekly hemodialysis a chance: revisiting the taboo. Nephrol Dial Transplant. 2014;29 (9):1618-1620. doi:10.1093/ndt/gfu096

6. Obi Y, Streja E, Rhee CM, et al. Incremental hemodialysis, residual kidney function, and mortality risk in incident dialysis patients: a Cohort Study. Am J Kidney Dis. 2016;68(2):256-265. doi:10.1053/ j.ajkd.2016.01.008 
7. Wong J, Vilar E, Davenport A, Farrington K. Incremental haemodialysis. Nephrol Dial Transplant. 2015;30(10):1639-1648. doi:10.1093/ndt/gfv231

8. Tangvoraphonkchai K, Davenport A. Incremental hemodialysis A European perspective. Semin Dial. 2017;30(3):270-276. doi:10.1111/sdi.12583

9. Zhang M, Wang M, Li H, et al. Association of initial twice-weekly hemodialysis treatment with preservation of residual kidney function in ESRD patients. Am J Nephrol. 2014;40(2):140-150. doi:10.1159/ 000365819

10. Kaja Kamal RM, Farrington K, Busby AD, et al. Initiating haemodialysis twice-weekly as part of an incremental programme may protect residual kidney function. Nephrol Dial Transplant. 2019;34 (6):1017-1025. doi:10.1093/ndt/gfy321

11. Caria S, Cupisti A, Sau G, Bolasco P. The incremental treatment of ESRD: a low-protein diet combined with weekly hemodialysis may be beneficial for selected patients. BMC Nephrol. 2014;15:172. doi:10.1186/1471-2369-15-172

12. Fernandez-Lucas M, Teruel-Briones JL, Gomis-Couto A, VillacortaPerez J, Quereda-Rodriguez-Navarro C. Maintaining residual renal function in patients on haemodialysis: 5-year experience using a progressively increasing dialysis regimen. Nefrologia. 2012;32 (6):767-776. doi:10.3265/Nefrologia.pre2012.Jul.11517

13. Park JI, Park JT, Kim YL, et al. Comparison of outcomes between the incremental and thrice-weekly initiation of hemodialysis: a propensity-matched study of a prospective cohort in Korea. Nephrol Dial Transplant. 2017;32(2):355-363. doi:10.1093/ndt/gfw332

14. Chertow GM, Levin NW, Beck GJ, et al.; Group FHNT. In-center hemodialysis six times per week versus three times per week. $N$ Engl $J$ Med. 2010;363(24):2287-2300. doi:10.1056/NEJMoa1001593

15. Suri RS, Larive B, Sherer S, et al. Risk of vascular access complications with frequent hemodialysis. J Am Soc Nephrol. 2013;24 (3):498-505. doi:10.1681/ASN.2012060595

16. Bieber B, Qian J, Anand S, et al. Two-times weekly hemodialysis in China: frequency, associated patient and treatment characteristics and quality of life in the China dialysis outcomes and practice patterns study. Nephrol Dial Transplant. 2014;29(9):1770-1777. doi:10.1093/ ndt/gft472

17. Daugirdas JT. Second generation logarithmic estimates of single-pool variable volume Kt/V: an analysis of error. J Am Soc Nephrol. 1993;4 (5):1205-1213. doi:10.1681/ASN.V451205

18. Amorim LD, Cai J. Modelling recurrent events: a tutorial for analysis in epidemiology. Int J Epidemiol. 2015;44(1):324-333. doi:10.1093/ ije/dyu222

19. Rhee CM, Obi Y, Mathew AT, Kalantar-Zadeh K. Precision medicine in the transition to dialysis and personalized renal replacement therapy. Semin Nephrol. 2018;38(4):325-335. doi:10.1016/j. semnephrol.2018.05.003

20. Murea M, Moossavi S, Garneata L, Kalantar-Zadeh K. Narrative review of incremental hemodialysis. Kidney Int Rep. 2020;5 (2):135-148. doi:10.1016/j.ekir.2019.11.014

21. Obi Y, Kalantar-Zadeh K. Incremental and once- to twice-weekly hemodialysis: from experience to evidence. Kidney Int Rep. 2017;2 (5):781-784. doi:10.1016/j.ekir.2017.07.006

Therapeutics and Clinical Risk Management

\section{Publish your work in this journal}

Therapeutics and Clinical Risk Management is an international, peerreviewed journal of clinical therapeutics and risk management, focusing on concise rapid reporting of clinical studies in all therapeutic areas, outcomes, safety, and programs for the effective, safe, and sustained use of medicines. This journal is indexed on PubMed Central, CAS,
22. Ocak G, Rotmans JI, Vossen CY, et al. Type of arteriovenous vascular access and association with patency and mortality. BMC Nephrol. 2013;14:79. doi:10.1186/1471-2369-14-79

23. Palmer BF, Henrich WL. Recent advances in the prevention and management of intradialytic hypotension. $J$ Am Soc Nephrol. 2008;19(1):8-11. doi:10.1681/ASN.2007091006

24. Chang TI, Paik J, Greene T, et al. Intradialytic hypotension and vascular access thrombosis. $J$ Am Soc Nephrol. 2011;22 (8):1526-1533. doi:10.1681/ASN.2010101119

25. Lee T, Roy-Chaudhury P. Advances and new frontiers in the pathophysiology of venous neointimal hyperplasia and dialysis access stenosis. Adv Chronic Kidney Dis. 2009;16(5):329-338. doi:10.1053/j.ackd.2009.06.009

26. Stracke S, Konner K, Kostlin I, et al. Increased expression of TGF-betal and IGF-I in inflammatory stenotic lesions of hemodialysis fistulas. Kidney Int. 2002;61(3):1011-1019. doi:10.1046/j.15231755.2002.00191.x

27. Obi Y, Rhee CM, Mathew AT, et al. Residual kidney function decline and mortality in incident hemodialysis patients. $J$ Am Soc Nephrol. 2016;27(12):3758-3768. doi:10.1681/ASN.2015101142

28. Shafi T, Jaar BG, Plantinga LC, et al. Association of residual urine output with mortality, quality of life, and inflammation in incident hemodialysis patients: the Choices for Healthy Outcomes in Caring for End-Stage Renal Disease (CHOICE) Study. Am J Kidney Dis. 2010;56(2):348-358. doi:10.1053/j.ajkd.2010.03.020

29. van der Wal WM, Noordzij M, Dekker FW, et al. Full loss of residual renal function causes higher mortality in dialysis patients; findings from a marginal structural model. Nephrol Dial Transplant. 2011;26 (9):2978-2983. doi:10.1093/ndt/gfq856

30. Marants R, Qirjazi E, Grant CJ, Lee TY, McIntyre CW. Renal perfusion during hemodialysis: intradialytic blood flow decline and effects of dialysate cooling. J Am Soc Nephrol. 2019;30(6):1086-1095. doi:10.1681/ASN.2018121194

31. Malik J, Kudlicka J, Lachmanova J, et al. Tissue ischemia worsens during hemodialysis in end-stage renal disease patients. $J$ Vasc Access. 2017;18(1):47-51. doi:10.5301/jva.5000630

32. Jofre R, Rodriguez-Benitez P, Lopez-Gomez JM, Perez-Garcia R. Inflammatory syndrome in patients on hemodialysis. $\mathrm{J} \mathrm{Am} \mathrm{Soc}$ Nephrol. 2006;17(12 Suppl 3):S274-280. doi:10.1681/ ASN.2006080926

33. Cobo G, Lindholm B, Stenvinkel P. Chronic inflammation in end-stage renal disease and dialysis. Nephrol Dial Transplant. 2018;33(suppl_3):iii35-iii40. doi:10.1093/ndt/gfy175

34. Costello-White R, Ryff CD, Coe CL. Aging and low-grade inflammation reduce renal function in middle-aged and older adults in Japan and the USA. Age (Dordr). 2015;37(4):9808. doi:10.1007/s11357015-9808-7

35. Kong JH, Davies MRP, Mount PF. Relationship between residual kidney function and symptom burden in haemodialysis patients. Intern Med J. 2021;51(1):52-61. doi:10.1111/imj.14775

\section{Dovepress}

EMBase, Scopus and the Elsevier Bibliographic databases. The manuscript management system is completely online and includes a very quick and fair peer-review system, which is all easy to use. Visit http://www.dovepress.com/testimonials.php to read real quotes from published authors. 